\title{
INTERNATIONAL CONFERENCE ON THE PEACEFUL USES OF ATOMIC ENERGY
}

$\mathrm{T}$ 1HE United Kingdom Government has accepted the invitation which was extended by the United Nations to eighty-four countries to participate in a conference on the peaceful uses of atomic energy, to open in Geneva on August 8 under the presidency of Dr. H. J. Bhabha, director of the 'Tata Institute of Fundamental Research, Bombay, and secretary of the Indian Atomic Einergy Commission. Prof. W. G. Whitman, head of the Department of Chemical Engineering in the Massachusetts Institute of Technology, will be secretary-general of the conference, and in this capacity will serve as an officer of the U.N. Secretariat, assisted by a working party consisting of Ralph J. Bunche and Ilya S. Tchernychev (U.N. Under-Secretaries) and Dr. Gunnar Randers (special consultant to the Secretary-General, Dag Hammarskjöld, in matters relating to the conference).

The conference, which is an outcome of proposals laid before the United Nations by President Eisenhower in December 1953 when he urged the need for international co-operation to apply the benefits of atomic energy to world peace, will be devoted to the presentation and discussion of papers on a number of main subjects related to the peaceful uses of atomic energy (see preliminary announcement, Nature, February 19, p. 328). It is intended that subjects will be dealt with and presented only from the scientific and technical points of view.

The United Kingdom Papers Committee, which has been set up under the chairmanship of Sir John Cockcroft, director of the Atomic Energy Research Establishment, Harwell, to integrate the United Kingdom's contribution to the conference, has drawn up a provisional list of papers and authors covering the majority of topics to be discussed. The Committee will be pleased to receive suggestions for titles and authors of additional papers, and communications should be addressed to the Secretary of the Papers Committee. Abstracts not exceeding five hundred words in length must be submitted to the Papers Committee on or before May 1, and the completed papers must be submitted on or before June 15.

The constitution of the U.K. Papers Committee is as follows: Sir John Cockcroft (chairman); Sir George Thomson (Royal Society); Dr. G. H. Daniel (Ministry of Fuel and Power); Dr. J. F. Loutit (Medical Research Council and Agricultural Research Council); Mr. P. Dankwerts (Industrial Group, Atomic Energy Authority); Mr. J. A. Jukes (Atornic Energy Authority); Dr. B. F. J. Schonland, Dr. J. V. Dunworth, Dr. R. Spence, and Dr. J. Gaunt (secretary) (Atomic Energy Research Establishment, Harwell).

It is unlikely that time will permit more than a small fraction of papers to be presented verbally; but all accepted papers will be published in the proceedings of the conference. Owing to shortage of accommodation, it is not certain that authors of papers will be able to attend all the sessions of the conference, even if their paper is accepted for verbal presentation. The final choice of papers will lie with the United Nations Advisory Committee, which is responsible for advising on conference arrangements.

The United Kingdom Government will contribute to the exhibition to be held in Geneva during the conference, and full details regarding it will be announced at a later date.

The plenary sessions of the conference will cover the following topics: $(A)$ and $(B)$, need for a new power source; $(C)$, the role of nuclear energy ; $(D)$, the building of a nuclear energy enterprise; $(E)$, health and safety aspects of nuclear energy ; $(F)$, production and use of isotopes, and problems relating to large quantities of radioactive substances. The sessions dealing with the need for a new power source will include survey papers on estimated world-power requirements in 1975 and 2000 , on the alternative sources of power, and on the needs of individual countries for power and heat. Session $C$ will include survey papers on the natural occurrence of uranium and thorium; each nation is being invited to furnish all available data, and the conference organization will make a summary of papers submitted, a few of which will be selected for presentation. Session $D$ will deal with the capital investment required for the development of nuclear energy and will include experience with existing plants. Session $E$ will consider the biological effects of radiation, including a discussion of human exposures which have occurred and the results of animal experiments, ecological problems arising from selective destruction of a given species in the food web, and the location of power reactors, with special consideration to the widespread dispersal of fission products. Session $F$ will include survey papers on the use of isotopes in science and industry, and also on the problems of long-term storage and disposal. Session $G$ will be concerned with what may be termed the present state of the art of handling large quantities of radioisotopes and the administrative and legal problems arising in the use of high-level radiation sources; this covers such matters as the training of industrial personnel, industrial safety, workman's compensation, etc.

In addition to the plenary sessions, there will be more specialized meetings devoted to specific topics. Under the heading of reactors, the programme mentions research reactors, power reactors including survey papers on fuel cycles and types of reactor, fast neutron reactors, thermal neutron reactors, and details of the running of prototypes of power reactors.

Sessions on technology are expected to cover such subjects as methods of prospecting for uranium and thorium, chemical treatment of the ores, production of uranium and thorium metal, analytical methods and the production technology of special materials such as heavy water, zirconium, beryllium and its oxide, and graphite. It is also hoped to have survey papers on chemical aspects of nuclear reactors, chemical processing of irradiated uranium and thorium fuel elements and the storage and separation of fission products. Other subjects included under the general heading of technology include the metallurgy of thorium, uranium and their alloys, fabrication of fuel elements, technology of liquid metals and the treatment and disposal of waste.

Reactor physics sessions will deal with equipment and techniques used in measuring cross-sections important for reactor design and the results obtained; selected topics such as neutron decay, certain $(n, \gamma)$ 
or $(\gamma, n)$ reactions, fission, $\gamma$-ray spectrum in fission, measurement of such quantities as the number of neutrons per fission, diffusion length, slowing-down length, transport mean free path and resonance integrals ; zero energy, exponential and critical (or model) experiments; reactor calculation techniques and comparison with experiment.

Sessions on reactor chemistry and metallurgy are expected to have survey papers on the fission process and the chemistry of its products, and the chemistry of the heavy elements, especially plutonium and neptunium. The problems involved in studying chemical reactions using highly radioactive materials, and the effects of radiation on materials used in reactors and also on solutions and metals, alloys and semiconductors, are also to be considered.

The biological and medical sessions will deal with such topics as the use of nuclear energy in medicine, for example, for diagnosis, therapy or tracer techniques, and in special public health problems such as the epidemiology of communicable disease, and the availability of rare elements in human nutrition. Genetic effects will also be considered in these sessions, covering both botany and zoology. Sessions will also be devoted to the biochemical and physiological uses of radioactive isotopes; use of nuclear energy in special problems of agriculture and forestry concerning plant genetics, movement of plant nutrients, pests, etc.; environmental mechanisms; and public health, including biological cycles of fission products in land and water organisms.

The topics to be considered in the sessions on the applications of radioisotopes to research and industrial problems include tracers in general research, developments in dosimetry, instrumentation and remote controls, applications of isotopes in process and quality control, and industrial utilization of fission products.

In addition to the specialized papers in the various sessions referred to, there will be a number of evening sessions at which leading men of science will deliver lectures of a more general character ; the topics to be discussed will be accelerators for particles, elementary particles, nuclear forces, nuclear structure, the neutron, isotopic dating, uses of radioactive substances in biology and medicine, free radicals and new elements.

\section{EMIL BEHRING AND PAUL EHRLICH* THEIR CONTRIBUTIONS TO SCIENCE By Prof. C. H. BROWNING, F.R.S.}

Emeritus Professor of Bacteriology, University of Glasgow

\section{Cancer Research}

$\mathrm{T}$ HE first results of Ehrlich's cancer investigations, which started late in 1901, were to demonstrate on an extensive scale the general impossibility of establishing tumours of one animal species in others. $\mathrm{He}$ also set about obtaining, in addition to Jensen's tumour, a series of transplantable tumours in mice which should be available for study. By giving a twenty-mark piece for every animal bearing a spontaneous tumour a large number were collected; the majority arose from the mammary gland in old

* Continued from p. 575 . female mice. Subcutaneous grafting in fresh animals established numerous strains, although very many failed to grow. On the analogy of infections, their 'virulence' increased on passage in the sense of the proportion of takes and the rate of growth. A minute study of their biology and structure indicated that the initial survival and subsequent growth of a fresh graft were closely associated with the angiotactic effect on the host's blood vessels. 'The microscopic structure depended considerably on the rate of growth. In addition to carcinomas, other classes of tumour were also propagated, for example chondroand osteo-sarcomas. A remarkable observation was the development of sarcoma in a strain of carcinoma and thereafter the successful separation of the two malignant components. 'The origin of the mixed tumour was attributed to some chemical effect of the carcinoma cells on those of the stroma. At the time, little was known of chemical carcinogens; but later observations presented the picture of what may be a closely analogous phenomenon. 'This was the production of sarcoma in mice from a phagocytic tissue which had developed in response to particles of a styryl quinoline compound resulting from precipitation of the dye in the tissues by the lymph4 Ehrlich approached the problem of acquired resistance to tumours by inoculating mice with a spontaneous tumour of negligible virulence; after 8-14 days, upwards of 50 per cent of the treated animals had become refractory to grafting with a highly virulent tumour, and this state lasted for some weeks or months. Normal tissues produced a similar effect. In spite of many interesting findings, the mechanism of acquired resistance to tumours still remains obscure, however.

The influence of nutritional factors on tumour growth interested Ehrlich deeply. He observed that a mouse tumour inoculated into rats grew vigorously for several weeks, but then receded; also transplants from the original rat to other rats failed to grow. On the other hand, the tumour could be maintained by alternate passages from rat to mouse. The conclusion drawn was that some nutritive material essential for growth is present in mice, but not in rats; hence the resistance of the latter was termed athrepsy. A number of other phenomena were also classed as athreptic ; but so far the conception has not proved fruitful for tumour pathology in general. The results of experiments on the chemotherapy of tumours were not published.

\section{Chemotherapy}

In 1891 Ehrlich, with Guttmann, published encouraging results in the treatment of malaria with methylene blue. From 1904 onward he concerned himself chiefly with chemotherapy. This work makes great demands on aptitude, patience and material resources, as well as luck (the ' 4 G's'-from the initials of the German words). His reputation as a scientist stood very high, and Frau Franziska Speyer, in memory of her husband, provided for the building and endowment of the Georg Speyer-Haus, to be devoted to research on chemotherapy, with facilities both for biological and chemical workers. When it started in 1906 there were three chemists and two biologists; soon the numbers increased. Already a very significant success had been achieved with trypan red, which in a single dose sterilized mice severely infected with $T$. equinum, the trypanosome responsible for a disease of horses in South America. 